\section{Biodiversity and Chemistry of Natural Products}

\section{by Russe// Kerr}

The IUPAC-sponsored conference on Biodiversity and Chemistry of Natural Products, held 13-18 July 2008 in Charlottetown, Prince Edward Island, Canada, was an amalgamation of the International Conference on Biodiversity and the International Symposium on the Chemistry of Natural Products. At the opening ceremony, the Right Honorable Robert Ghiz, the premier of the Province of Prince Edward Island, formally welcomed the 200 conference participants and spoke about the tremendous growth in natural products planned for PEI over the next five years.

Twenty outstanding scientists from academia, government, and industry gave plenary and invited talks; another 38 short talks were presented by an equally diverse group. Speakers represented 20 countries; poster presenters represented 28. Symposia topics included isolation and structure elucidation, biosynthesis, spectroscopy, synthesis, engineered biosynthesis, natural products as anticancer leads, new methods in natural products chemical ecology, metabolomics, and genomics. One highlight was the Royal Society of Chemistry's "Natural Product Reports" lecture award by Jason Micklefield (University of Manchester) on the biosynthetic engineering of nonribosomal lipopeptides.

In addition to a stimulating scientific program, social events were very popular. For A banquet on the beach.

the opening reception, participants were led from the conference hotel to an informal dinner by re-enactors dressed in clothing of the mid-1800s, who spoke about the history of Canada, noting that Charlottetown was the country's "birthplace."

The meeting concluded with acknowledgements to the generous conference sponsors and presentations to the student poster award winners, Sutaporn Bunyajetpong (University of Prince Edward Island) and Arthur Lelono (Ehime University). Mary Garson presented an overview of the next meeting in this series, to be held in Brisbane, Australia.

Russell Kerr <rkerr@upei.ca〉 is research chair in Marine Natural Products at the University of Prince Edward Island, Charlottetown, PEl, Canada.

\section{Vanadium}

\section{by João Costa Pessoa}

The 6th International Vanadium Symposium (V6 Symposium) was held 17-19 July 2008 at the Calouste Gulbenkian Foundation, Lisbon, Portugal. The IUPAC-sponsored conference was supported by the Portuguese Chemical Society and organized by the Centro Química Estrutural, Instituto Superior Técnico in Lisbon. João Costa Pessoa was conference chairman, and Hitoshi Michibata (Hiroshima University, Japan) and Kan Kanamori (University of Toyama, Japan) were co-chairmen. Tamás Kiss (University of Szeged, Hungary) represented IUPAC at the meeting.

Interest in vanadium science can be traced back to 1986 , when the very first vanadium meeting was held within the Federation of American Societies for Experimental Biology Meeting. The main purpose of this sixth meeting was to facilitate discussions about all aspects of vanadium science, including such topics such as chemistry, biological chemistry, therapeutic applications, and new materials and technology of vanadium compounds.

More than 100 participants from 26 countries took part in the conference. Most well-known experts in the field and many young researchers were present. No plenary lectures were planned; instead, many oral communications (56) were included to encourage as much participation as possible, to establish an informal atmosphere, and to stimulate interaction among attendees.

The 2008 Vanadis Award was given to Toshikazu Hirao, of the Graduate School of Engineering, Osaka University, Japan. The Vanadis Award is given to a researcher for her or his contributions to vanadium science, especially for having displayed innovative research that has a documented impact on the direction of the field.

In early 2009, special issues containing contributions from this meeting will be published in the Journal of Inorganic Biochemistry and in Pure and Applied Chemistry.

João Costa Pessoa <joao.pessoa@mail.ist.utl.pt> is a professor at the Instituto Superior Técnico, Lisbon, Portugal.

www.vanadiumsix.com 